\title{
Correlates of asthma morbidity in primary care
}

\author{
K P Jones, D J G Bain, M Middleton, M A Mullee
}

\begin{abstract}
Objectives - To explore the morbidity of patients diagnosed as asthmatic in general practice, to examine the determinants of this morbidity, and to derive a simple morbidity screening tool for use in primary care.
\end{abstract}

Design-Patient interviews, lung function measurements, and data extraction from general practice case notes.

Subjects -300 asthmatic patients aged 5 to 65 years randomly selected from the repeat prescribing registers of three general practices in the Southampton area.

Main outcome measures-Reported morbidity using a calculated index based on three questions (Are you in a wheezy or asthmatic condition at least once per week; Have you had time off work or school in the past year because of your asthma; Do you suffer from attacks of wheezing during the night?); mean forced expiratory volume in one second and mean peak expiratory flow (over a seven day period); diurnal variation in peak flow; and the relation of the morbidity index to lung function.

Results-Mean forced expiratory volume in one second was $67 \%$ predicted (SD 18.4), mean peak expiratory flow was $80 \%$ predicted (SD 18.9), and mean diurnal variation was $10 \%$ (SD 7.7). 76 subjects were classified as having low morbidity, 95 medium, and 125 high. The morbidity index was significantly associated with forced expiratory volume in one second, mean peak expiratory flow rate, and diurnal variation $(p<0.05)$; it was not significantly associated with inhaler technique or use of prophylaxis.

Conclusions - There was a large burden of persisting morbidity across all ages of patients diagnosed as asthmatic in the three well resourced practices studied. The use of the morbidity index may help to target the asthmatic patients needing more attention by concentrating on those reporting medium to high morbidity.

Group, Faculty of

Medicine, University of

Southampton, Aldermoor

Health Centre,

Southampton SO1 6SY

K P Jones, MRCGP, senior lecturer

D J G Bain, MD, professor

$M$ Middleton, SRN, research nurse

Medical Statistics and Computing, University of Southampton,

Southampton General

Hospital, Southampton SO9 4XY

M A Mullee, MSC, senior

statistical programmer

Correspondence to:

Dr Jones.

BMf 1992;304:361-4 by improving patient or doctor education in Britain have shown that it is difficult to have any notable impact on outcome. ${ }^{13-15}$ Innovations in asthma care in general practice that might contribute towards improvements include regular surveillance through clinics run by nurses ${ }^{16}$ and the use of self management protocols by patients. ${ }^{17}$

The evaluation of such innovations will require simple measures of morbidity that can be applied in general practice. A range of measures has been used to date. Hilton $e t$ al found that over half of their sample of asthmatic patients were avoiding activities because of their asthma and that work or school was being missed on average 1.22 times per year. ${ }^{13}$ White et al reported breathlessness at least once a week in $47 \%$ of their sample and night wakening at least once a week in $30 \%{ }^{15}$ Turner-Warwick found that $73 \%$ of a large sample of patients with symptoms of asthma were waking at least once a week and $39 \%$ every night. ${ }^{18}$ Horn and Cochrane also found considerable self reported morbidity from a questionnaire in one practice that had identified only $3.5 \%$ of patients on its list as asthmatic. ${ }^{19}$ Gellert et al examined all the case records of one inner London general practice and found a cumulative prevalence of recorded diagnosis of asthma of $7 \cdot 2 \%$ in adults and $19 \cdot 5 \%$ in children aged 15 years and younger. ${ }^{20}$

This study explores the burden of morbidity in patients receiving repeat prescriptions for asthma drugs in three well resourced general practices and derives a simple morbidity index for use in general practice. This index should enable practices both to discover which of their asthmatic patients require more urgent assistance and to evaluate the success of such assistance.

\section{Methods}

Three general practices in the Southampton area were selected for study: North Baddesley Health Centre (5500 patients); Nightingale Surgery, Romsey (6500 patients); and Aldermoor Health Centre $(8100$ patients), which also incorporates the Primary Medical Care Group at Southampton University. All three were innovative practices ${ }^{21}$ based in modern, purpose built premises, with practice managers in post and full primary care teams, computers, A4 sized records, vocational trainees, and a teaching commitment to the medical school. The mean list size was fewer than 2000 patients per general practitioner. Each practice had an asthma register, and altogether $1172(5 \cdot 8 \%)$ patients were listed.

Asthmatic patients were identified from the computerised repeat prescribing registers in each practice by searching for all patients taking anti-asthma drugs as defined in the respiratory section of the British National Formulary. One hundred patients in each practice aged between 5 and 65 years were then randomly selected from those so identified. The samples from the two well matched, purely service 
practices were selected first, and the random samples proved to have a very close age mix. In the third practice random selection was stratified to ensure a similar age mix.

The patients' general practitioners excluded 18 subjects as unsuitable for interview, and these were replaced with further randomly selected subjects from the prescribing registers. Each selected patient was invited to participate in the study by a letter signed by his or her own general practitioner. Patients were contacted by one of us (MM), verbal consent obtained, and a date and time for interview arranged. Written consent for patients' notes to be inspected was also recorded. Fifty six declined to enter the study at this point and were replaced, again by random selection.

The interviews were conducted by the research nurse (MM) mostly in the patients' own homes but a few, by request, were conducted at the surgery. Interviews comprised an extended questionnaire derived from the instruments designed and used by Hilton et $a l,{ }^{22}$ including information on demography, self reported morbidity, knowledge of asthma, use and knowledge of treatment, self care ability, attitudes to asthma, and inhaler technique. Inhaler technique was scored on a simple, pragmatic five point scale for each delivery system, as previously described. ${ }^{23}$ In addition, lung function (forced expiratory volume in one second, forced vital capacity, and peak expiratory flow) was measured at the time of interview with a turbine spirometer. ${ }^{24}$

A mini-Wright peak flow meter was left with the patient, who completed a seven day, twice daily peak flow diary after instruction. Diurnal variation was calculated as the absolute difference between the two values for the day expressed as a percentage of the mean of the two values. Mean diurnal variation was thus the average of this variable across all the days recorded in the diary. ${ }^{25}$ Subjects aged over 15 completed the interview alone, but children under this age completed it with parental help. Subsequently, patient records were examined and data concerning treatment, peak flow recordings, and numbers of consultations in the year before interview were extracted.

Ethical permission for this study was given by the district ethical committee at Southampton General Hospital.

Categorical morbidity variables from the questionnaire and some items such as numbers of hospital admissions and outpatient visits from the patient records were converted to dichotomous variables. The answers to the six main dichotomised morbidity variables (as itemised below) were coded so that each combination of answers within a case had a unique numeric code (from 0 to 63 ). Analysis of the code frequencies then allowed the three variables most often positive to be selected to comprise a morbidity index. The associations between the morbidity index and other variables were then analysed by using the $\chi^{2}$ test with Yates's correction for continuity. Continuous variables, when normally distributed, were compared by using one way analysis of variance; when they were skewed they were either rendered categorical or analysed with the Kruskal-Wallis analysis of variance. All analyses were carried out with the SPSS PC (version 3.1) or SPSS X packages. ${ }^{2627}$

\section{Results}

Four subjects, despite being on the repeat prescribing register, had not received any drugs for asthma in the year before interview and were therefore excluded, leaving 296 cases for further analysis. There were 164 male and 132 female patients in the sample; the median age was 22.8 years (interquartile range 12.2 to 42.5 years). The median age in completed years at which asthma started was 7 years (interquartile range 3 to 20 years). Morbidity results, together with measures of lung function, inhaler technique and usage of inhaler aids are summarised in table $I$.

\section{CALCULATING THE MORBIDITY INDEX}

Six main dichotomised variables were used: a wheezy or asthmatic condition at least once per week; asthma that gets so bad that it interrupts daily life at least once per month; having to avoid activities between attacks; everyday activities being affected quite a lot or a great deal by asthma in the past 12 months; time off from work or school in the past year; and attacks of wheezing during the night. A total of 144 patients answered yes to being in a wheezy or asthmatic condition at least once a week; 76 had had time off work or school in the past year; and 149 had attacks of wheezing during the night. Only 13 of the 233 patients who gave any positive responses did not

TABLE I-Demographic associations with index of morbidity from asthma

\begin{tabular}{|c|c|c|c|c|c|c|}
\hline & \multirow{2}{*}{$\begin{array}{c}\text { No of } \\
\text { patients }\end{array}$} & \multicolumn{2}{|c|}{ Sex } & : & \multicolumn{2}{|l|}{ Morbidity } \\
\hline & & Male & Female & Low & Medium & High \\
\hline \multicolumn{7}{|l|}{ Age: } \\
\hline${ }_{5-}$ & 100 & 61 & 39 & 28 & 33 & 39 \\
\hline $15-$ & 51 & 33 & 18 & 12 & 10 & 29 \\
\hline $25-$ & 40 & 19 & 21 & 10 & 17 & 13 \\
\hline 35 & 43 & 20 & 23 & 10 & 15 & 18 \\
\hline 45 & 20 & 10 & 10 & 7 & 5 & 8 \\
\hline $55-66$ & 42 & 21 & 21 & 9 & 15 & 18 \\
\hline Total & 296 & 164 & 132 & 76 & 95 & 125 \\
\hline \multicolumn{7}{|l|}{ Social class: } \\
\hline & 30 & 18 & 12 & 6 & 12 & 12 \\
\hline II & 95 & 46 & 49 & 28 & 36 & 31 \\
\hline III Non-manual & 32 & 19 & 13 & $\begin{array}{r}20 \\
6\end{array}$ & 13 & 13 \\
\hline III Manual & 64 & 36 & 28 & 16 & 18 & 30 \\
\hline IV & 28 & 17 & 11 & 10 & 4 & 14 \\
\hline $\mathrm{v}$ & $\begin{array}{r}20 \\
6\end{array}$ & 6 & & 1 & $\begin{array}{l}4 \\
3\end{array}$ & $\begin{array}{r}14 \\
2\end{array}$ \\
\hline Student & 1 & 1 & & & 1 & \\
\hline Unemployed & 5 & 5 & & & $i$ & 4 \\
\hline Retired & 26 & 12 & 14 & 7 & 4 & 15 \\
\hline Unknown & 9 & 4 & 5 & 2 & 3 & 4 \\
\hline Total & 296 & 164 & 132 & 76 & 95 & 125 \\
\hline
\end{tabular}

TABLE II -Morbidity, lung function, and use of aids in patients with asthma

\begin{tabular}{|c|c|}
\hline \multirow{2}{*}{\multicolumn{2}{|c|}{ No $(\%)$ with morbidity $(n=296)$}} \\
\hline & $145(49)$ \\
\hline Asthma or wheezing interrupts daily life at least monthly & $33(11)$ \\
\hline Avoids mild exercise between attacks & $13(4)$ \\
\hline Avoids energetic sports between attacks & $56(19)$ \\
\hline Avoids parties and social gatherings between attacks & $18(6)$ \\
\hline Avoids at least some activities between attacks & $69(23)$ \\
\hline $\begin{array}{l}\text { Everyday activities affected quite a lot or a great deal in } \\
\text { past } 12 \text { months }\end{array}$ & $28(10)$ \\
\hline Asthma worse in past year & $46(16)$ \\
\hline Stayed off work or school because of asthma: & \\
\hline Ever & $151(60)^{\star}$ \\
\hline In past year & $77(31)^{\star}$ \\
\hline Attacks of wheezing during night & $150(51)$ \\
\hline When wakened, sleeps again with difficulty or not at all & $52(17)$ \\
\hline Smoking: & \\
\hline Current smokers & 42(14) \\
\hline Formerly regular smokers & $35(12)$ \\
\hline Passive smokers & $69(23)$ \\
\hline Pets: & $191(65)$ \\
\hline Dogs & $107(36)$ \\
\hline Cats & $68(23)$ \\
\hline Birds & $33(11)$ \\
\hline Lung function & \\
\hline Mean (SD) $\mathrm{FEV}_{1}$ as percentage of predicted $(\mathrm{n}=255)$ & $66 \cdot 8(18 \cdot 5)$ \\
\hline $\begin{array}{l}\text { Mean (SD) forced vital capacity as percentage of predicted } \\
(\mathrm{n}=256)\end{array}$ & $81 \cdot 1(19 \cdot 0)$ \\
\hline $\begin{array}{l}\text { Mean (SD) peak flow as percentage of predicted }(n=244) \\
\text { Mean (SD) diurnal variation in peak flow }(n=284)\end{array}$ & $\begin{array}{r}79 \cdot 9(18 \cdot 9) \\
10 \cdot 1(7 \cdot 7)\end{array}$ \\
\hline Inhaler technique and $\mathrm{No}(\%)$ using aids & \\
\hline Proper inhaler technique (score 5/5) & $142(48)$ \\
\hline Poor inhaler technique (score $3 / 5$ or less) & $65(22)$ \\
\hline Large chamber spacers & $64(23)$ \\
\hline Small spacers & $11(4)$ \\
\hline Nebulisers & $11(4)$ \\
\hline Peak flow meters & $25(9)$ \\
\hline
\end{tabular}

$\mathrm{FEV}_{1}=$ force
${ }^{\star} \mathrm{n}=249$. 
say yes to one or more of these three questions. The responses to these three questions were therefore used to derive a morbidity index. Those subjects answering no to all three questions were regarded as the low morbidity group; one yes equalled medium morbidity, and two or three yes answers equalled high morbidity. There were 76 patients in the low morbidity group, 95 in the medium group, and 125 in the high group. Table II shows the distribution of the three groups by age and social class.

\section{ASSOCIATIONS OF THE MORBIDITY INDEX}

The morbidity index was not significantly associated with the following variables: age, inhaler technique, use of prophylaxis, use of short courses of oral steroids, current smoking, and visits to outpatient departments. There was a trend towards rising morbidity with lower social class, but this did not reach significance. Patients in the higher morbidity groups were more likely to have been admitted to hospital (table III). Table III also shows the relation of the index to forced expiratory volume in one second and mean peak expiratory flow rate from the week's diary (as a percentage of predicted value), and diurnal variation (the difference between the two values expressed as a percentage of their mean). With two sample $t$ tests, the differences in the means of forced expiratory volume in one second and mean peak expiratory flow rate were significant only when the high and low morbidity groups were compared $(t=2 \cdot 51, \mathrm{p}=0.013$ for both). The differences for diurnal variation were significant for each pair (low $v$ high, $t=-5 \cdot 43, \mathrm{p}<0 \cdot 001$; low $v$ medium, $t=-2 \cdot 76$, $\mathrm{p}=0.006 ;$ medium $v$ high, $t=-2 \cdot 48, \mathrm{p}=0.014)$.

\section{Discussion}

The levels of morbidity from asthma expressed by patients in the three practices were high. We found $23 \%$ of patients admitting to avoiding some activities between attacks, which was lower than Hilton et al's $57 \%,{ }^{13}$ but our figure of $49 \%$ in a wheezy or asthmatic condition at least once a week is the same as that found

TABLE III - Variables associated with morbidity index

\begin{tabular}{|c|c|c|c|c|c|}
\hline & \multicolumn{3}{|c|}{ Morbidity index } & \multirow[b]{2}{*}{$\chi^{2}$} & \multirow[b]{2}{*}{$\mathrm{p}$ Value } \\
\hline & Low & Medium & High & & \\
\hline \multicolumn{6}{|l|}{ Social class: } \\
\hline I-III Non-manual & 40 & 61 & $56\}$ & $5 \cdot 20$ & \multirow{2}{*}{0.07} \\
\hline III Manual-V & 27 & 25 & $46\}$ & $\mathrm{df}=2$ & \\
\hline \multicolumn{6}{|l|}{ Age: } \\
\hline $5-$ & 28 & 33 & 39 & & \multirow{4}{*}{0.95} \\
\hline $15-$ & 22 & 27 & 42 & 1.59 & \\
\hline $35-$ & 17 & 20 & 26\lceil & $\mathrm{df}=6$ & \\
\hline \multirow{2}{*}{\multicolumn{6}{|c|}{ Inhaler technique: }} \\
\hline & & & & & \\
\hline Score $=5$ & 39 & 47 & 56 & 0.97 & \multirow{2}{*}{$0 \cdot 62$} \\
\hline Score $<5$ & 35 & 44 & $65\}$ & $\mathrm{df}=2$ & \\
\hline \multicolumn{6}{|l|}{ Prophylaxis: } \\
\hline Yes & 52 & 68 & $86\}$ & 0.22 & \multirow{2}{*}{0.89} \\
\hline No & 24 & 27 & $38\}$ & $\mathrm{df}=2$ & \\
\hline \multicolumn{6}{|l|}{ Oral steroid courses: } \\
\hline Yes & 13 & 18 & $36 !$ & 4.59 & \multirow{2}{*}{$0 \cdot 10$} \\
\hline No & 62 & 73 & $87\}$ & $\mathrm{df}=2$ & \\
\hline \multicolumn{6}{|l|}{ Smoking: } \\
\hline Yes & 9 & 12 & $20\}$ & $0 \cdot 86$ & \multirow{2}{*}{0.65} \\
\hline No & 67 & 83 & $105\}$ & $\mathrm{df}=2$ & \\
\hline \multicolumn{6}{|l|}{ Outpatient visits: } \\
\hline Yes & 7 & 4 & $10\}$ & $1 \cdot 85$ & \multirow{2}{*}{$0 \cdot 40$} \\
\hline No & 69 & 90 & $113\}$ & $\mathrm{df}=2$ & \\
\hline \multicolumn{6}{|l|}{ Hospital admissions: } \\
\hline Yes & 1 & 1 & $8\}$ & $6 \cdot 15$ & \multirow{2}{*}{$0 \cdot 05$} \\
\hline No & 75 & 93 & $115\}$ & $\mathrm{df}=2$ & \\
\hline \multicolumn{6}{|l|}{ Peak flow measured: } \\
\hline Yes & 39 & 53 & $85\}$ & $7 \cdot 35$ & \multirow{2}{*}{$0 \cdot 03$} \\
\hline No & 37 & 42 & $38\}$ & $\mathrm{df}=2$ & \\
\hline \multicolumn{6}{|c|}{ Mean percentage $(S D)$ of predicted values } \\
\hline $\mathrm{FEV}_{1}$ & $\begin{array}{c}71 \cdot 1(16 \cdot 4) \\
(n=64)\end{array}$ & $\begin{array}{c}67 \cdot 8(17 \cdot 7) \\
(n=82)\end{array}$ & $\begin{array}{c}63 \cdot 6(19 \cdot 7) \\
(\mathrm{n}=109)\end{array}$ & $\begin{array}{c}3 \cdot 55^{\star} \\
\mathrm{df}=2\end{array}$ & $0 \cdot 03$ \\
\hline Mean peak flow & $\begin{array}{c}84 \cdot 5(15 \cdot 6) \\
(n=61)\end{array}$ & $\begin{array}{c}80 \cdot 4(18 \cdot 8) \\
(n=80)\end{array}$ & $\begin{array}{c}76 \cdot 8(20 \cdot 3) \\
(\mathrm{n}=103)\end{array}$ & $\begin{array}{l}3 \cdot 24^{\star} \\
\mathrm{df}=2\end{array}$ & $0 \cdot 04$ \\
\hline Diurnal variation in peak flow & $\begin{array}{c}6 \cdot 9(5 \cdot 7) \\
(n=72)\end{array}$ & $\begin{array}{c}9 \cdot 7(7 \cdot 3) \\
(n=93)\end{array}$ & $\begin{array}{r}12 \cdot 4(8 \cdot 3) \\
(\mathrm{n}=119)\end{array}$ & $\begin{array}{l}12 \cdot 62^{\star} \\
\mathrm{df}=2\end{array}$ & $<0.001$ \\
\hline
\end{tabular}

${ }^{\star} F$ ratio (one way analysis of variance).

\section{Morbidity index}

Are you in a wheezy or asthmatic condition at least once a week?

Have you had time off work or school in the past year because of your asthma?

Do you suffer from attacks of wheezing during the night?

$$
\begin{array}{ll}
\text { No to all questions } & =\text { low morbidity } \\
\text { One yes } & =\text { medium morbidity } \\
\text { Two or three yeses } & =\text { high morbidity }
\end{array}
$$

by White et al. ${ }^{15}$ Our $51 \%$ of patients with night time awakening and $31 \%$ missing work or school in the year before interview also are comparable with the results of Hilton $e t$ al and Turner-Warwick. ${ }^{13} 18$

This study provides further evidence that there is a large burden of continuing morbidity in patients diagnosed as asthmatic, even those on the lists of well organised practices. Hargreave et al have described adequate control as "minimal symptoms, ideally none, normal activities of daily living, airflow rates normal or near normal at rest, daily variation of peak expiratory flow rate $<20 \%$, ideally $<10 \%$. ${ }^{28}$ From our results it would seem that asthmatic patients in the practices described may be less than adequately controlled, but this is probably due to a combination of factors.

In our work and other studies ${ }^{13151819}$ patients are either not receiving sufficient treatment of their asthma or are lowering their expectations of life to fit with their symptoms - that is, they are "turning down their life thermostat." Before concluding that less than optimum treatment is being offered, the possibility has to be considered that the treatments available are still not effective in achieving the aims set out by Hargreave et al or that their criteria for adequate control are unrealistic.

Our finding that only $48 \%$ of asthmatic patients were judged to have proper inhaler technique provides further evidence that the effective delivery of drugs to patients' airways continues to be a problem. ${ }^{29-33}$

Two biases may have affected our sample. Firstly, sampling with replacement of those unwilling to participate risks those included being slightly unrepresentative, but the size of the sample makes the likely effect small. Secondly, our definition of asthma used as an entry criterion for the study - the repeat prescription of anti-asthma drugs - may have had two effects. It may have biased the sample towards including patients with rather more severe asthma, omitting those who obtain their asthma drugs only at consultations. This proportion is likely to be fairly small in well organised practices. Another possible effect of the entry criterion is that some patients with fixed or irreversible airways obstruction may have been entered. The age range of the sample, 5-65 years, should have helped to minimise the consequences of this. Analysis of the associations of the morbidity index for the 5-45 year age group showed only broadly similar results.

Before any form of proactive care or regular review of asthmatic patients can get underway in general practice the patients have to be identified and ranked according to need. Neville has given some guidelines for case finding, ${ }^{34}$ but the sheer number of asthmatic patients already known about (let alone those still to be diagnosed) make priority setting important. All asthmatic patients are potentially at risk of severe attacks and therefore of death, but certain risk factors can be identified, such as a history of severe attacks and a recent discharge from hospital. ${ }^{35}$ The majority of patients will not be highlighted by this approach and it 
is here that the morbidity index proposed in this study is a useful method for identifying "at risk" patients.

The morbidity index is extremely simple (box) and applicable in several circumstances. It avoids using isolated lung function measurements, which may be especially difficult if different instruments have been used to make the recordings, ${ }^{36}$ but this study has shown that the index relates to lung function both for single readings and over one week of home recording. Furthermore, it divided asthmatic patients in this study approximately into thirds across all age bands and social classes. The index may be used opportunistically to identify the level of morbidity or may be part of regular follow up in proactive care programmes. Another possibility that we are currently testing is its suitability for postal "morbidity screening." Directing proactive care initially to patients with high morbidity is likely to make best use of inevitably limited resources.

In conclusion, this study confirms the burden of persisting morbidity across all ages of patients diagnosed as asthmatic even in the three well resourced general practices studied. Improvement is likely to involve modifications in drug prescribing and also planned care. The use of the morbidity index described here may be a help in giving priority to asthmatic patients in particular need of more attention in the near future.

KPJ was a Sir Jules Thorn research fellow during this study and $M M$ was supported by the Wessex Medical School Trust. The spirometers were purchased with a grant from the British Lung Foundation and the peak flow meters were kindly donated by Clement Clarke International Ltd. We thank Bonnie Sibbald of St George's Hospital Medical School Department of General Practice for all her help with the methods used in this work; Dr Ann-Louise Kinmonth, reader in primary medical care, and Dr Mike Campbell, senior lecturer in medical statistics, for their useful comments; and all the staff of the three practices for their enthusiasm and support.

1 Holgate ST, Finnerty JP. Recent advances in understanding the pathogenesis of asthma and its clinical implications. $Q \mathcal{F}$ Med 1988;66:5-19.

2 Jackson RT, Sears MR, Beaglehole R, Rea HH. International trends in asthma mortality, 1970-1985. Chest 1988;94:914-9.

3 Burney PGJ. Asthma mortality in England and Wales: evidence for a further increase. Lancet 1986;ii:323-6.

4 Evans R, Mullally DI, Wilson RW, Gergen PJ, Rosenberg HM, Grauman JS, et al. National trends in the morbidity and mortality of asthma in the US. Prevalence, hospitalization and death from asthma over two decades: 1965-1984. Chest 1987;91:65-74S.

5 Mao Y, Semenciw R, Morrison H, MacWilliams L, Davies J, Wigle D. Increased rates of illness and death from asthma in Canada. Can Med Assoc $\mathcal{F}$ $1987 ; 137: 620-4$
6 Sly RM. Mortality from asthma. $\mathcal{F}$ Allergy Clin Immunol 1988;82:705-17. Anderson HR. Trends and district variations in the hospital care of childhood asthma: results of a regional study 1970-85. Thorax 1990;45:431-7.

8 Mitchell EA. International trends in hospital admission rates for asthma. Arch Dis Child 1985;60:376-8.

9 Burney PGJ, Chinn S, Rona RJ. Has the prevalence of asthma increased in children? Evidence from the national study of health and growth 1973-86. BMF 1990;300:1306-10.

10 British Thoracic Association. Death from asthma in two regions of England. BMF 1982;285:1251-5.

11 Jones KP. Asthma - still a challenge for general practice. $\mathcal{F} R$ Coll Gen Pract 1989;39:254-6.

12 Management of asthma in the community [editorial]. Lancet 1989;ii: 199-200.

13 Hitton S, Sibbald B, Anderson HR, Freeling P. Controlled evaluation of the effects of patient education on asthma morbidity in general practice. Lance 1986; ; :26-9.

14 Jenkinson D, Davison J, Jones S, Hawtin P. Comparison of effects of a self management booklet and audiocassette for patients with asthma. $B M J$ 1988;297:267-70.

5 White PT, Pharoah CA, Anderson HR, Freeling P. Randomised controlled trial of small group education on the outcome of chronic asthma in genera practice. $f R$ Coll Gen Pract 1989;39:182-6.

16 Charlton I, Charlton G, Broomfield J, Mullee M. Evaluation of peak flow and symptoms only self-management plans for control of asthma in general practice. BMF 1990;301:1355-9.

17 Beasley R, Cushley M, Holgate ST. A self management plan in the treatment of adult asthma. Thorax 1989;44:200-4.

18 Turner-Warwick M. Nocturnal asthma: a study in general practice. $\mathcal{f} R$ Coll Gen Pract 1989;39:239-43.

19 Horn CR, Cochrane GM. An audit of morbidity associated with chronic asthma in general practice. Respir Med 1989;83:71-5.

20 Gellert AR, Gellert SL, Iliffe SR. Prevalence and management of asthma in London inner city general practice. Br f Gen Pract 1990;40:197-201.

21 Bosanquet N, Leese B. Family doctors and innovation in general practice. $B M \mathcal{F} 1988 ; 296: 1576-80$

22 Hilton S, Sibbald B, Anderson HR, Freeling P. Evaluating health educatio in asthma-developing the methodology: preliminary communication. $f R$ Soc Med 1982;75:625-30.

23 Jones KP, Middleton M. Benefits of an inhaler-technique scoring system. Update 1989;38:1399-403.

24 Gonawardena KA, Houston K, Smith AP. Evaluation of the turbine pocket spirometer. Thorax 1987;42:689-93.

25 Higgins BG, Britton JR, Chinn S, Jones TD, Jenkinson D, Burney PGJ, Tattersfield AE. The distribution of peak expiratory flow variability in a population sample. Am Rev Respir Dis 1989;140:1368-72.

26 Norusis MJ. The SPSS guide to data analysis for SPSS/PC+. Chicago: Statistical Package for the Social Sciences, 1989.

27 Norusis MJ. SPSSX Introductory statistics guide. Chicago: Statistical Package for the Social Sciences, 1983.

28 Hargreave FE, Dolovich J, Newhouse MT. The assessment and treatment of asthma: a conference report. $\mathcal{F}$ Allergy Clin Immunol 1990;85:1098-111.

29 Crompton GK. Problems patients have using pressurized aerosol inhalers. Eur $\mathcal{F}$ Respir Dis 1982;63:101-4.

30 Horsley MG, Bailie GR. Risk factors for inadequate use of pressurized aerosol inhalers. F Clin Pharm Ther 1988;13:139-43.

31 Allen S, Prior A. What determines whether an elderly patient can use metered dose inhaler correctly? Br $\mathcal{A}$ Dis Chest 1986;80:45-9.

32 Pedersen S, Frost L, Arnfred T. Errors in inhalation technique and efficiency in inhaler use in asthmatic children. Allergy 1986;41:118-24.

33 Hilton $S$. An audit of inhaler technique among asthma patients of 34 general practitioners. Br $\mathcal{F}$ Gen Pract 1990;40:505-6.

34 Neville R. Case finding of asthma patients. Practitioner 1990;234:417-8.

35 Strunk RC. Workshop on the identification of the fatality-prone patient with asthma. Summary of workshop discussion. I Allergy Clin Immunol 1987; 80(suppl):455-7.

36 Jones KP, Mullee M. Measuring peak expiratory flow in general practice: comparison of mini-Wright peak flow meter and turbine spirometer. $B M \mathcal{J}$ 1990;300:1629-31.

(Accepted 10 October 1991)
An elderly woman, with a cavernous angioma occupying much of the right middle fossa, had to have the trigeminal (and oculomotor) nerves on this side sacrificed in its resection. The face, cheek, and outer aspect of the tongue on this side were thus deprived of all sensation.

In the four years which have elapsed since surgery the patient has experienced bizarre and persistent sensations, or "illusions": a sense that her right temple is "deformed," that the whole right side of her face is "slipping," "unstable," "caved in," or "missing," or that it is tremendously swollen inside and that it looks grotesque. While the patient allows that her face looks normal in a photograph, she cannot overcome the sense of its deformity with a mirror. She recently had to have a leg amputated (for unrelated causes) and soon after surgery became aware of a phantom. "Now," she said, "I know what's wrong with my face. It's exactly the same feelingI have a phantom face."

Grotesque illusions of facelessness and facial deformity were common when antimony was given for trigeminal neuralgia - this caused necrosis of the trigeminal nerves bilaterally. And most of us, probably, have had strange phantom experiences at the dentist-a sense, as the procaine hydrochloride takes hold, of a grotesquely swollen, deformed, or misplaced cheek or tongue. If both inferior dental nerves are anaesthetised there may be a sudden illusion of jawlessness, or agnathia (this so alarmed patients when this procedure was common that dentists gave it up, and now anaesthetise one side at a time). Neither looking, nor reason, serve to correct these illusions, for they are the expression of real body image disturbances, complex cerebral reactions to denervation. Only the return of normal sensation can dispel these phantoms.

Although so common, so bizarre, and so distressing (and, if there is permanent deafferentation, incorrigible), such "phantom faces" are hardly ever discussed in textbooks of neurology.-OLIVER SACKs, consultant neurologist in New York 